\title{
OPTIMAL VIEWING POSITION OF PARTIALLY CONNECTED AND UNCONNECTED WORDS IN ARABIC
}

Dr. Deia Ganayim, Arab Center for Mind, Brain \& Behavior (ACMBB), Sakhnin, Israel E-mail: info@acmbb.org.il

Received: October, 22.2015.

Revised: November, 17.2015. Accepted: November, 21.2015. Original Article

UDK 159.946.4.075

003.332.5:159.93.4.072

\begin{abstract}
In order to assess the unique reading processes in Arabic, given its unique orthographic nature of natural inherent variations of inter-letter spacing, the current study examined the extent and influence of connectedness disparity during single word recognition using the optimal viewing position (OVP) paradigm. The initial word viewing position was systematically manipulated by shifting words horizontally relative to an imposed initial viewing position. However, unlike previous research, partially connected/unconnected three-, four- and five-letter Arabic words were displayed in the left and right visual hemifields at all possible locations of letter fixation. It was found that OVP effects occurred during the processing of isolated Arabic words. No OVP was found in three-letter words; for four- and five-letter words, the OVP effect appeared as a U-shaped curve with a minimum towards the second and third letters. Thus, the OVP effects generalize across structurally different alphabetic scripts. Furthermore, a perceptual superiority was found for words with right-positioned unconnected sub-units as compared to left positioned unconnected sub-units because of the differential sensitivity of the hemispheres to the gestalt form of letters. Such findings support the established view that the LH specializes in word recognition for alphabetic languages.
\end{abstract}

Keywords: arabic, connected/unconnected words, optimal viewing position, right/left visual field, word recognition.

\section{INTRODUCTION}

The Optimal Viewing Position (OVP) is a well-known phenomenon in visual word recognition (O'Regan and Jacobs, 1992; Stevens and Grainger, 2003). The OVP is assessed by shifting words horizontally at different offsets to the left and right of a central fixation position between two vertically aligned fixation lines so that participants fixate at all possible let-

Corresponding Author

Dr. Deia Ganayim, Arab Center for Mind, Brain \&

Behavior (ACMBB), Sakhnin, Israel

E-mail: info@acmbb.org.il ter fixation locations within each word (Brysbaert, 1994; Hunter, Brysbaert and Knecht, 2007) (Figure 1). The OVP effect reflects how the initial horizontal placement of the fixation position in a word constrains its recognition (Brysbaert and Nazir, 2005; Rayner, 1998).

Studies on OVP have found that words are recognized fastest and with fewest errors when a reader's gaze is fixated in a region between the beginning of a word and its center (Van der Haegen, Drieghe and Brysbaert, 2010). As the initial fixation position deviates from the OVP, recognition time increases at a rate of 20-30 ms per letter (O'Regan, LevySchoen, Pynte and Brugaillere, 1984). This OVP has been observed in many tasks, including word naming, lexical decision-making, and perceptual identification; these results have been observed in different languages, including French, Dutch, Hebrew, Arabic, and Japanese (Brysbaert and Nazir, 2005).

Brysbaert and Nazir, (2005) proposed that the OVP results from the interplay of numerous factors that play a role in visual word recognition. These factors including lexical constraints, letter visibility, perceptual learning and hemispheric lateralization may contribute jointly to word recognition performance (Yao-N'Dré Castet and Vitu, 2013).

Lexical constraints and informativeness (information structure of the word stimuli) affect the OVP since the first letters contain most of the information about a word's identity because they are shared by a smaller number of words in the lexicon (known as orthographic neighbors) (Yao-N'Dré et al., 2013). About words that share all but one letter in the correct stimulus position, research has demonstrated that low-frequency words with at least one high-frequency orthographic neighbor are harder to recognize than those with no such high-frequency neighbors (Grainger, 1990; Grainger, O'Regan, Jacobs and Segui, 1989; Grainger and Segui, 1990).

The visibility of letters to each side of 
the fixation position (a perceptual span in reading) affect the OVP since the visual acuity of letters decreases with increased distance from the fixation position; there is also greater crowding when retinal eccentricity increases. Therefore, greater letter information is available when the eyes' initial fixation is near the center of a word. Even at an eccentricity of 1 degree, there is already $40 \%$ deterioration in visual acuity (Wertheim, 1894). Words presented a few letter positions to the left or to the right of the fixation position are, therefore, difficult to recognize. The center of vision is generally estimated to subtend 3 degrees of visual angle, with some three or four letters per degree of visual angle.

In line with these findings, the shape of the OVP curve varies with the visual characteristics of a particular stimulus. Nazir, Heller, and Sussmann (1992) varied inter-letter spacing and showed that the slopes of the curves became gradually greater as spacing increased, alongside increases in the eccentricity of each letter. Additionally, Nazir, Jacobs, and O'Regan (1998) scaled letters in words proportionally to their distance from the fixation location and found flatter OVP curves.

Additionally, perceptual learning based on reading habits affect the OVP since fixating on a word's beginning makes word recognition easier, because eyes tend to land at a word's beginning and frequently fixated locations improve reading performance (Nazir, Ben-Boutayab, Decoppet, Deutsch and Frost, 2004). Accordingly, variations in word identification performance with retinal location would result from the preferred viewing position effect, or the tendency, in languages read from left to right, for the eyes to land more near the center, or slightly to the left, of words (Rayner, 1979). Left-to-right-reading adults should be better at identifying words within the central or right-to-central part of their visual field because that is where they have adapted to visualize words while learning to read (Chung, Legge and Cheung, 2004). Yet, there is no clear leftward asymmetry of the OVP effect in languages read from right to left, such as Arabic or Hebrew (Farid and Grainger 1996; Nazir et al., 2004).

Hemispheric lateralization is another factor affecting the OVP since words presented in the left visual field (LVF) are projected to the right hemisphere (RH), and information from the right visual field (RVF) is sent to the left hemisphere (LH) (Stevens and Grainger, 2003), with the fovea of each eye divided precisely at its vertical meridian (Brysbaert,
2004; Jordan and Paterson, 2009; Lavidor and Walsh, 2004; Lindell and Nicholls, 2003; Shillcock, Ellison and Monaghan, 2000). A word recognition advantage has been shown when letters in a word (or the entire word) are presented to the right of the fixation rather than the left. This reflects unilateral projection to $\mathrm{LH}$ and $\mathrm{RH}$ on either side of the fixation position (Paterson, Jordan and Kurtev, 2009), because the left cerebral hemisphere plays a greater role in language processing (Brysbaert, 1994, 2004) and the split-fovea processing (Brysbaert, 1994; Brysbaert, Vitu and Schroyens, 1996; Hunter et al., 2007; Lavidor, Ellis, Shillcock and Bland, 2001; Martin, Thierry, Démonet, Roberts and Nazir, 2007). Whitney's (2001) SERIOL model argues that foveal letters assemble in the dominant hemisphere before recognition starts. This would mean that letters from a word's beginning (in RVF) are directly sent to the LH, but have to be temporarily inhibited until letters from the word's end (in LVF) are transferred from the RH to LH (Van der Haegen and Brysbaert, 2011). Despite the converging evidence in support of a functional split in human foveal processing, it is still a controversial claim with respect to the precision of foveal splitting and how far the effects of foveal splitting extend from the retina into the higher processing associated with visual word recognition.

In a letter discrimination task, previous research has found (Bouma, 1973; Legein and Bouma, 1977; Legge, Mansfield and Chung, 2001; Stevens and Grainger, 2003) that the likelihood of correctly identifying a letter embedded in a string of homogeneous letters decreases faster in the left, compared to the right visual field.

Although, several factors may be responsible for the shape of OVP curves, visual factors appear to have the greatest role (YaoN'Dré, Castet and Vitu, 2013). In another study by Nazir et al., (1998), the OVP effect was canceled out when word letters were scaled as a function of their eccentricity and leading to letter visibility.

The OVP pattern found in isolated words could provide key insights into understanding visual word recognition processes (Brysbaert et al., 1996; Clark and O'Regan, 1999; O'Regan and Jacobs, 1992), especially when investigating Arabic, with its unique visual connectedness. 


\subsection{Arabic orthography}

Arabic orthography is unique and complex: dots are part of the grapheme, and letters have a similar basic form differentiated by the number and location of the dots $(\dot{H}, \overrightarrow{ })$ ). Dots appear in 15 letters: 10 letters with one dot, 3 letters with two dots, and 2 letters with three dots, leading to the great visual similarity between the letters. This letter similarity causes recognition errors (Blommaert, 1988; Bouma, 1971; Briggs and Hocevar, 1975; Cattell, 1896; Gervais, Harvey and Roberts, 1984; Geyer, 1977; Gibson, Osser, Schiff and Smith, 1963; Loomis, 1982; Townsend, 1971a, 1971b; Townsend and Ashby, 1982; Townsend, Hu and Evans, 1984; Watson and Fitzhugh, 1989). Some letters have different forms that depend on their position in the word while the letter's basic form is preserved within these different forms (Abd El-Minem, 1987). Twenty-two letters out of 28 letters have 4 different letterforms (Table 1): a separate or basic form $(\diamond)$, an initial form connecting to the left $(\bowtie)$, a medial form connecting to the right and left $(\mathrm{t})$, and a final form connecting to the right (d). Since most of the Arabic letters are similar in their basic form, precise recognition of these Arabic letterforms and their writing rules is essential for word recognition. This process consumes attentional resources (Abu Rabia, 2001), slowing the grapheme-phoneme conversion process (Taouk and Coltheart, 2004).

Table 1. Arabic letters (connecting, unconnecting) in different shapes as a function of word-position

\begin{tabular}{|c|c|c|c|c|}
\hline & Basic & Initial & Medial & Final \\
\hline \multicolumn{5}{|c|}{ Connecting Letters } \\
\hline 1 & ب ب & 4 & + & 4 \\
\hline 2 & ت & I & 1 & 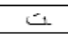 \\
\hline 3 & ت & I & $I$ & $ت$ \\
\hline 4 & $\varepsilon$ & $ج$ & $?$ & $\bar{\varepsilon}$ \\
\hline 5 & 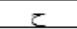 & 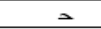 & 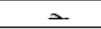 & $z$ \\
\hline 6 & $\bar{\varepsilon}$ & $\dot{x}$ & $\dot{1}$ & $i$ \\
\hline 7 & نט & ثـ & 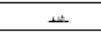 & W \\
\hline 8 & تَ & 5 & 立. & ju \\
\hline 9 & صט & صد & ص & ص \\
\hline 10 & ضن & ض & ش & ضن \\
\hline 11 & b & b & b & b. \\
\hline 12 & E & E & E & b. \\
\hline 13 & $\varepsilon$ & c & $x$ & $\varepsilon$ \\
\hline 14 & $\dot{\varepsilon}$ & $\dot{c}$ & $\dot{z}$ & $\dot{\varepsilon}$ \\
\hline 15 & $\dot{\theta}$ & 彦 & $\underline{\underline{z}}$ & e \\
\hline 16 & تق & $\underline{\underline{g}}$ & $\underline{\underline{a}}$ & 3. \\
\hline 17 & 5 & 5 & 5 & 디 \\
\hline 18 & J & I & $I$ & 4 \\
\hline 19 & 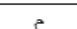 & s & s & م \\
\hline 20 & ن & I & $i$ & i \\
\hline 21 & . & $\rightarrow$ & 4 & 4 \\
\hline 22 & ي & $\frac{1}{2}$ & \pm & 5 \\
\hline \multicolumn{5}{|c|}{ Unconnecting Letters } \\
\hline 1 & 1 & 1 & l & 1 \\
\hline 2 & د & ב & 2 & $\perp$ \\
\hline 3 & $\dot{j}$ & $\dot{j}$ & $\dot{1}$ & $\dot{1}$ \\
\hline 4 & נ & נ & 2 & $j$ \\
\hline
\end{tabular}

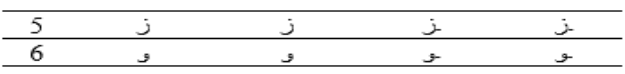

Most of the letters connect from both sides (referred to as connecting letters) while six unconnecting letters $(1) \dot{J}$ j g) connect to the right only. Accordingly (and distinctly from other languages), Arabic words can consist of one unit where the words contain no unconnecting letters (without inter-letter spaces: home ( ), or consist of several sub-units where the words contain several unconnecting letters (with inter-letter spaces: home 1دار). Consequently, Arabic orthography consists of words with different forms which depend on the number and position of the unconnecting letter strings in the word: connected words (without inter-letter spaces, where all the letters are connected), unconnected words (with inter-letter spaces, where all of the letters are unconnected), mixed words (with some interletter spaces, where some letters are connected and some are not) (Table 2). A previous study found that in a corpus of 262,647 words, the average number of letters was 4.3 , with a subunit average of 2.2 per word (with one interletter space). Sub-units are an important point of focus because computerized optical recognition studies of Arabic handwriting have suggested that the sub-unit, rather than the word, is the basic unit of recognition (Belaid and Choisy, 2008).

Table 2. Arabic word forms of partially connected and unconnected 3-letters, 4-letters and 5-letters (- represents a within word Space, $\square$ represents a Connecting letter, $\square$ represents an Unconnecting letter)

\begin{tabular}{|c|c|c|c|}
\hline & 5-Letters word & 4-Letters word & $\begin{array}{c}\text { 3-Letters } \\
\text { word }\end{array}$ \\
\hline 1 & प्र००-प & प्पि-व & प्र-व \\
\hline 2 & प्र०-०० & प्र-पर & प-व० \\
\hline 3 & प्र-प्ये & प-वप् & \\
\hline 4 & प-जकप्र & प्र-०-口 & \\
\hline 5 & 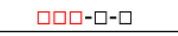 & व-ロ०-८ & \\
\hline 6 & प०-००-८ & प-८-५० & \\
\hline 7 & 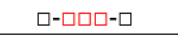 & & \\
\hline 8 & 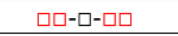 & & \\
\hline 9 & 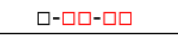 & & \\
\hline 10 & प-口-पवर & & \\
\hline 11 & 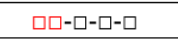 & & \\
\hline 12 & 口-प०-口- & & \\
\hline 13 & 口-व-प०-口 & & \\
\hline 14 & 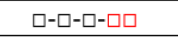 & & \\
\hline
\end{tabular}

It is worth to mention that, Arabic indeed has a nonconcatenative morphology in which the root and some other letters of a word pattern intermingle to create the desired inflectional or derivational meaning. Thus, it often happens that Arabic readers cannot rely on the beginning of the word to identify written words. Farid and Grainger, 1996 found that the initial fixation curves in Arabic depended on the morphological structure of the stimuli. Prefixed words produced a leftward 
(word ending) advantage whereas suffixed words produced a rightward (word beginning) advantage. In the present study, we used words with the first, second and third letters to be root letters. Indeed, root letters that are of special importance for word recognition are concentrated in our study towards the beginning (as in Latinate languages).

\subsection{The present study}

To date, previous research has only examined OVP in long Arabic words (Farid and Grainger, 1996), and occurrence and effect of fixation disparity in single word recognition tasks are yet to be assessed. Accordingly, the present study examined the extent and influence of connectedness disparity during single word recognition using the OVP paradigm (three-, four- and five-letter stimuli presented at a normal reading size, at all possible locations). In line with previous research, we used the initial fixation-letter paradigm in a naming or recognition task. However, unlike previous research, partially connected/unconnected Arabic words were used (Table 3 ).

Additionally, three experiments were conducted to assess the recognition of partially connected/unconnected Arabic words (Experiments 1,2,3) displayed in the left and right visual hemifields at all possible locations of letter fixation (Table 3). Previous research that has investigated hemispheric influences on recognition of Arabic words (Ibrahim and Eviatar, 2009) and other languages that read from right to left (Adamson and Hellige, 2006) indicated a LH superiority for words. Additionally, several studies indicate that the RH is particularly poor at identifying Arabic letters (Eviatar, Ibrahim and Ganayim, 2004), which may be exacerbated by the poor discriminability of individual letters and additional crowding (Pelli et al., 2007).

Table 3. Outline of the study experiments

\begin{tabular}{ccc}
\hline Experiments & Word Length & Words Type \\
\hline $\begin{array}{c}\text { Experiment } \\
1\end{array}$ & 3-Letter & $\begin{array}{c}\text { Left positioned unconnected } \\
\text { vs. } \\
\text { Right positioned unconnected }\end{array}$ \\
\hline $\begin{array}{c}\text { Experiment } \\
2\end{array}$ & 4-Letter & $\begin{array}{c}\text { Left positioned unconnected } \\
\text { vs. } \\
\text { Right positioned unconnected }\end{array}$ \\
\hline $\begin{array}{c}\text { Experiment } \\
3\end{array}$ & 6-Letter & $\begin{array}{c}\text { Left positioned unconnected } \\
\text { vs. }\end{array}$ \\
& & Right positioned unconnected \\
\hline
\end{tabular}

The study hypotheses address partially connected/unconnected Arabic word levels at all possible locations of letter fixation. The study questions at the partially connected/unconnected Arabic word level (Experiments 1, $2,3)$ were as follows:

1. Is word readability affected by the visual differentiations of partially connected/unconnected Arabic word forms, particularly for right- and left-positioned unconnected subunits? We expected that the performance should be superior for partially connected/unconnected words with right positioned unconnected sub-units when compared to left positioned unconnected sub-units.

2. Is the Arabic OVP affected by the visual differentiation of partially connected/unconnected word forms? We expected that the Arabic OVP would be in the central fixation position, in accordance with previous research.

3. Does the word length effect exist in partially connected/unconnected Arabic words? We expected to find the length effect reflected in longer naming times for long words, supporting the sequential processing model of visual word recognition.

\section{MATERIALS AND METHODS}

\section{EXPERIMENT 1}

Experiment 1 addressed the influence of Arabic word forms on visual word recognition; specifically, it assessed how connected (or unconnected) left or right sub-units of the word affect word recognition. The goal of this experiment was to explore the OVP of partially unconnected (right: unconnected from the first letter, left: unconnected from the last letter) three-letter word forms. An initial fixation paradigm was used to present words in all possible letter fixation positions. The participants were asked to read (i.e., recognize) all the words in a naming task. We note that this is the first study to examine whether the OVP is modulated by visual features of partially connected and unconnected three-letter Arabic words, and the resultant effects on reading. 


\subsection{Method}

2.1.1. Variables. The independent variables were the position of the unconnected sub-units relevant to the word's center (right: unconnected from the first letter; left: unconnected from the last letter) and the initial fixation letter (first, second, third). The dependent variables were the accuracy rate and the response times for each word condition. The experiment had a within-subjects $2 \times 3$ bi-factorial design.

2.1.2. Participants. A total of 41 university students participated in the study (average age: $22.7, \mathrm{SD}=2 ; 20$ males and 21 females). All were right-handed native Arabic speakers of middle socio-economic status who displayed normal or corrected-to-normal vision in both eyes. No participants had a history of neurological or emotional disorders. Participants, being university students, were assumed to read at a satisfactory level, and none was formally diagnosed as having reading impairments.

2.1.3. Stimuli. The stimuli were two new lists of 10 three-letter words, each varying according to the position of the unconnected sub-units relevant to the word's center (right: unconnected from the first letter, left: unconnected from the last letter) and presented in all positions of the initial fixation letter (first, second, third). The words were nouns selected from primary and secondary school textbooks, as well as those occurring in the dictionary with medium frequency (2.5-3.5) in accordance with previous studies (Abdelhadiet al., 2011; Khateb et al., 2014), as judged by 52 university students on a 1-5 frequency scale (1=very rare, $2=$ rare, $3=$ average, $4=$ frequent, $5=$ very frequent). The words were displayed in white 24-point Simplified Arabic Fix font on a black background of a PC screen (Table 4). The words were introduced randomly.
Table 4. Word Stimuli and frequency (frequency scale: $1=$ very rare, $2=$ rare, $3=$ average, $4=$ frequent, $5=$ very frequent) used in the different experiments

\begin{tabular}{|c|c|c|c|c|c|}
\hline \multirow[t]{2}{*}{ Experiments } & \multirow[t]{2}{*}{$\begin{array}{l}\text { Word } \\
\text { Length }\end{array}$} & \multicolumn{2}{|c|}{$\begin{array}{l}\text { Left positioned } \\
\text { unconnected }\end{array}$} & \multicolumn{2}{|c|}{$\begin{array}{l}\text { Right positioned } \\
\text { unconnected }\end{array}$} \\
\hline & & Word & Frequency & Word & Frequency \\
\hline \multirow{10}{*}{ Experiment 2} & \multirow{10}{*}{ 3-Letter } & تصدة & 3.5 & î & 3.5 \\
\hline & & حذة & 2.8 & ل1 & 3.5 \\
\hline & & بوم & 3.1 & ذنة & 3.5 \\
\hline & & ضنأن & 2.5 & Sis & 3.5 \\
\hline & & جذع & 3.5 & إبل & 2.5 \\
\hline & & خدن & 2.9 & رعب & 3.5 \\
\hline & & ili & 3.5 & رنفي & 3.4 \\
\hline & & سرع & 2.6 & نj & 3.3 \\
\hline & & 每 & 3.4 & و & 3.5 \\
\hline & & عرع & 3.2 & زيل & 3.5 \\
\hline \multirow{12}{*}{ Experiment 4} & \multirow{12}{*}{ 4-Letter } & \multicolumn{2}{|c|}{$\begin{array}{c}\text { Left positioned } \\
\text { unconnected }\end{array}$} & \multicolumn{2}{|c|}{$\begin{array}{l}\text { Right positioned } \\
\text { unconnected }\end{array}$} \\
\hline & & Word & Frequency & Word & Frequency \\
\hline & & عوبد & 3.5 & ألمبه & 3.5 \\
\hline & & ع عزرةً & 2.6 & 宓 & 2.9 \\
\hline & & بلزرةً & 3.2 & $4{ }^{3}$ & 2.6 \\
\hline & & غزروةٌ & 3.1 & لرعه & 2.9 \\
\hline & & بزئة & 3.5 & لونه & 3 \\
\hline & & جولدة & 3 & إريت & 3.1 \\
\hline & & كارة & 2.2 & أن & 2.7 \\
\hline & & مازة & 2.3 & ترعث & 2.3 \\
\hline & & 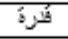 & 3.5 & روعة & 2.3 \\
\hline & & سلرةة & 2.7 & ندلة & 3.4 \\
\hline \multirow{12}{*}{ Experiment 6} & \multirow{12}{*}{ 5-Letter } & \multicolumn{2}{|c|}{$\begin{array}{c}\text { Left positioned } \\
\text { unconnected }\end{array}$} & \multicolumn{2}{|c|}{$\begin{array}{l}\text { Right positioned } \\
\text { unconnected }\end{array}$} \\
\hline & & Word & Frequency & Word & Frequency \\
\hline & & عهبأن & 2.5 & أنبهم & 3.5 \\
\hline & & ف & 3.5 & أن & 2.9 \\
\hline & & هجران & 3.4 & أ & 2.6 \\
\hline & & لغزأن & 4.5 & لرعهة & 2.9 \\
\hline & & 4tulu & 3.5 & لدونهم & 3 \\
\hline & & نجدان & 2.6 & إنُهم & 3.1 \\
\hline & & نكران & 2.8 & روتهم & 2.3 \\
\hline & & نتالن & 3.4 & ورنهה & 2.3 \\
\hline & & فُ & 2.9 & ردعهה & 2.7 \\
\hline & & صنولن & 2.5 & وركهم & 3.5 \\
\hline
\end{tabular}

2.1.4. Procedure. A CRT display (19 inches) was placed at a viewing distance of 60 $\mathrm{cm}$ from the participant. There were 60 trials. Each trial contained the following steps using super lab software:

1. Two vertical fixation lines were presented in the middle of the screen for $300 \mathrm{~ms}$.

2. The word stimulus was presented for $150 \mathrm{~ms}$ between the lines with the letter that was to be fixated within the word was placed between the lines. Fixating on the first letter meant that the word was shifted to the left

3. The fixation lines remained on the screen until the voice key registered a response, or until a time-out of $1500 \mathrm{~ms}$ was reached (Figure 1). A break was provided after 30 (threeletter words) trials, or whenever the 
participant indicated that (s)he needed a break.

Figure 1. Time course of one trial in the optimal viewing position task

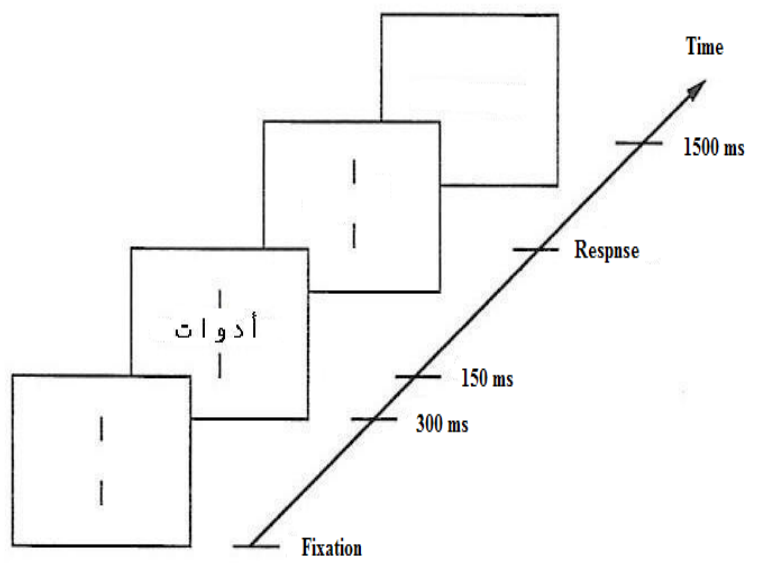

Participants received notice that there would be an Arabic word between two vertical lines in the middle of the screen. It was stressed, explicitly and repeatedly, that it was important to fixate between the two lines when these lines were presented. Participants were asked to name the words as quickly and as accurately as possible. They were informed that they could ask for a break whenever they wanted.

Each participant was tested individually in a random presentation sequence of the words. The response time was a measurement of the time between the presentation of a word and the onset of a spoken response, at which onset is defined acoustically. The word noted by the participant was written by the experimenter.

\subsection{Results}

Because the accuracy percentage exceeded $99 \%$ in all conditions, an analysis of accuracy was not conducted. The differences in reading time according to the two types of words (right unconnected: unconnected from the first letter, left unconnected: unconnected from the last letter) and their initial fixation letters (first, second, third letter) were tested with an RM-ANOVA. There was a significant effect of the unconnected sub-units position ( $\mathrm{F}$ $(1,40)=6.75, \mathrm{p}<0.013)$, with reaction time for the right positioned unconnected sub-units (Mean $=364, \mathrm{SD}=107$ ) being significantly shorter than for left positioned unconnected sub-units $($ Mean $=380, \mathrm{SD}=113)($ Figure 3$)$. However, the effect of the initial fixation letter was not significant $(\mathrm{F}(2,39)=0.561, \mathrm{p}=$
$0.575)$ (Figure 3). The interaction between the factors was non-significant $(\mathrm{F}(2,39)=0.767$, $\mathrm{p}=0.471)$ (Figure 2).

Figure 2. Reaction time as a function of the position of the unconnected word's sub-units (right, left) and their initial fixation letters (first, second, third letter). Note: Error bars represent standard error

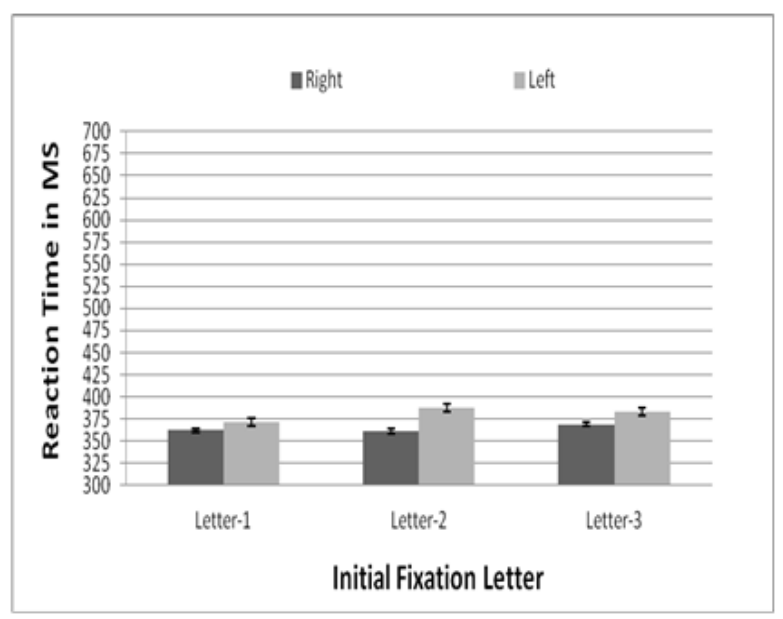

\subsection{Discussion}

No OVP effect was observed and all reaction times were similar for partially connected/unconnected three letter Arabic words since these short words can be read with one fixation compared with long words (Almabruk et al., 2011; Hyönä and Bertram, 2011; Liu and Li, 2013; White et al., 2012).

A perceptual superiority was found for partially connected/unconnected three letter Arabic words with right-positioned unconnected sub-units as compared to left positioned unconnected sub-units. This occurred because letter discriminability into the right of fixation locations is especially good (Jordan and Paterson, 2009; Jordan and Paterson, 2010) and because of the differential sensitivity of the hemispheres to the gestalt form of letters (Hsiao, Cipollini and Cottrell, 2013). Such findings support the established view that states the LH specialize in word recognition for alphabetic languages; it also provides further evidence that an $\mathrm{LH}$ advantage also occurs for languages that are read from right to left, such as Arabic (Ibrahim and Eviatar, 2009).

\section{EXPERIMENT 2}

Experiment 2 addressed the influence of Arabic word form-reflected in the position of the unconnected sub-units relevant to 
the word's center (right: unconnected from the first and second letters, left: unconnected from the third and last letters) — of four-letter words on visual word recognition. Specifically, it examined how connected (or unconnected) left or right sub-units of the word affect word naming, and aimed to explore the OVP of partially unconnected (right: unconnected from the first and second letters, left: unconnected from the third and last letters) four-letter word forms. An initial fixation paradigm was used to present words in all possible letter fixation positions. The participants were asked to read all the words in a naming task. We note that this is the first study to examine whether the OVP is modulated by visual features of partially connected and unconnected four-letter Arabic words, and its resultant effects on reading.

\subsection{Method}

3.1.1. Variables. The independent variables were the position of the unconnected sub-units relevant to the word's center (right: unconnected from the first and second letters, left: unconnected from the third and last letters) and the initial fixation letter (first, second, third, fourth). The dependent variables were the accuracy rate and the response time for each word condition. The experiment had a within-subjects $2 \times 4$ bi-factorial design.

3.1.2. Participants. A total of 22 university students participated in the study (average age: $26.3, \mathrm{SD}=6,10$ males and 12 females). All were right-handed native Arabic speakers of middle socio-economic status with normal or corrected-to-normal vision in both eyes. No participants had a history of neurological or emotional disorders. Participants, being university students, were assumed to read at a satisfactory level, and none was formally diagnosed as having reading impairments.

3.1.3. Stimuli. The stimuli were two new lists of 10 four-letter words, each varying according to the position of the unconnected sub-units relevant to the word's center (right: unconnected from the first and second letters, left: unconnected from the third and last letters), and presented in all positions of the initial fixation letter (first, second, third, fourth). The words were nouns selected from primary and secondary school textbooks, as well as those occurring in the dictionary with medium frequency $(2.5-3.5)$ in accordance with previous studies (Abdelhadi et al., 2011; Khateb et al., 2014), as judged by 52 university students on a $1-5$ frequency scale $(1=$ very rare,
$2=$ rare, $3=$ average, $4=$ frequent, $5=$ very frequent). The words were displayed in white 24-point Simplified Arabic Fix font on a black background of a PC screen (Table 4). The words were introduced randomly.

3.1.4. Procedure. The procedure was largely same as that of Experiment 1 but included a total numbers of 80 trials.

\subsection{Results}

Because the accuracy percentage exceeded $99 \%$ in all conditions, an analysis of accuracy was not conducted. The differences in reading time according to the position of word sub-units (right, left) and the initial fixation letter (first, second, third, and fourth letter) were tested with an RM-ANOVA. We found a significant effect of unconnected sub-units position (right, left) $(\mathrm{F}(1,21)=6.33, \mathrm{p}<0.02)$, with reaction time for right positioned unconnected sub-units (Mean $=384, \mathrm{SD}=150$ ) being significantly shorter than for corresponding left sub-units (Mean $=399, \mathrm{SD}=156)$. We also found a significant initial fixation letter effect $(\mathrm{F}(3,19)=3.81, \mathrm{p}<0.03)$, with Posthoc paired sample $t$-tests showing that the reaction time for the second and third fixation letters being similar but shorter than for the first and fourth fixation letters (Figure 3). The interaction between the factors was not significant $(F(3,19)=0.34, p=0.795)$ (Figure 4).

Figure 3. Reaction time for four-letter words as a function of the initial fixation letter (first, second, third, and fourth letter). Note: Error bars represent standard error

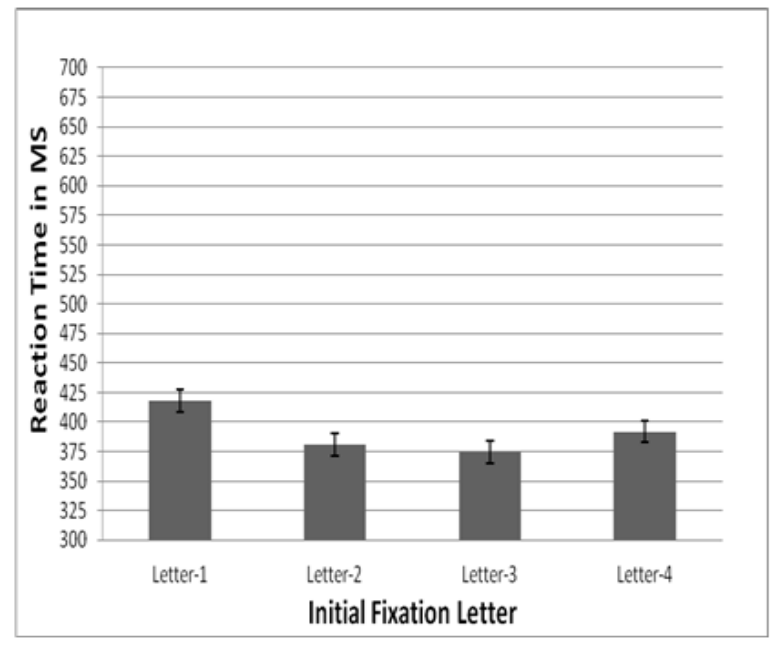


Figure 4. The reaction time of four-letter words as a function of the position of unconnected word subunits (right, left) and initial fixation letter (first, second, third, and fourth). Note: Error bars represent standard error

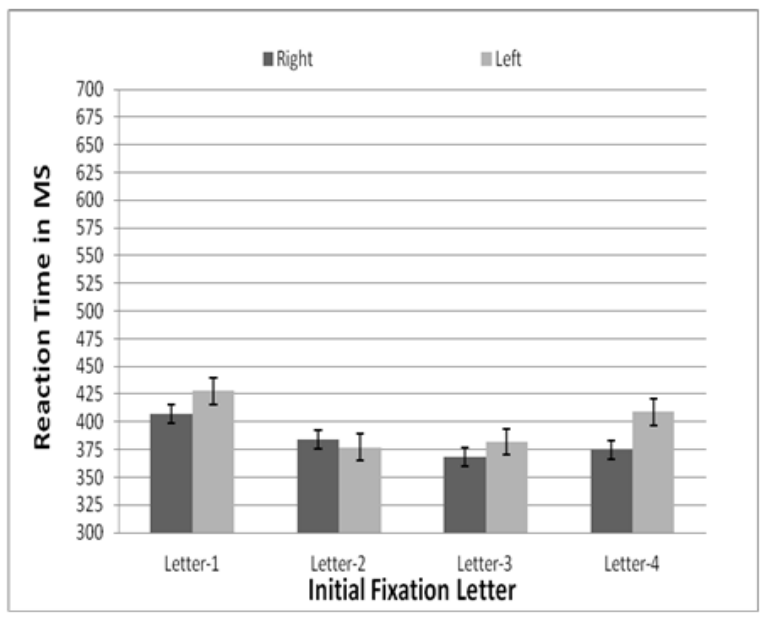

\subsection{Discussion}

For four letter words, we observed a Ushaped curve of reaction time, as a function of initial viewing position with a minimum towards the second and third letter. This OVP effect, could be explained by two factors: (1) The drop in visual acuity with retinal eccentricity especially for long words (Hyönä and Bertram, 2011; O'Regan et al., 1984), (2) the placement of most information used for word recognition between the word's beginning and its center (Broerse and Zwaan, 1966; Brysbaert and Nazir, 2005; Eriksen and Eriksen, 1974; Li and Pollatsek, 2011; White et al., 2008; Yan et al., 2006).

Taking all together the readability of letters into the right of fixation is better than into the left of fixation (Jordan and Paterson, 2009; Jordan and Paterson, 2010), the differential global-local processing of the hemispheres (Hsiao et al., 2013) with the LH advantage in visual word recognition (Ibrahim and Eviatar, 2009), a perceptual advantage was found for partially connected/unconnected four letter Arabic words with right-positioned unconnected sub-units as compared to left positioned unconnected sub-units in line with Experiment 2 .

\section{EXPERIMENT 3}

Experiment 3 addressed the influence of Arabic word form on visual word recognition; in particular, it examined how connect- ed (or unconnected) left or right sub-units of the word affect word recognition, and aimed to explore the OVP of partially unconnected (right, left) five-letter word forms. An initial fixation paradigm was used to present words in all possible letter fixation positions. The participants were asked to read all the words in a naming task. We note that this is the first study to examine whether the OVP is modulated by visual features of partially connected and unconnected five-letter Arabic words, and the resultant effects on reading.

\subsection{Method}

4.1.1. Variables. The independent variables were the position of unconnected subunits relative to the word's center (right, left) and the initial fixation letter (first, second, third, fourth, and fifth). The dependent variables were the accuracy rate and the response time of each word condition. The experiment had a within-subjects $2 \times 5$ bi-factorial design.

4.1.2. Participants. A total of 34 university students participated in the study (average age: $29.1, \mathrm{SD}=8,14$ males and 20 females). All were right-handed native Arabic speakers of a middle socio-economic status who displayed normal or corrected-to-normal vision in both eyes. No participants had a history of neurological or emotional disorders. Participants, being university students, were assumed to read at a satisfactory level, and none was formally diagnosed as having reading impairments. All were right-handed native Arabic speakers of a middle socio-economic status who displayed normal or corrected-tonormal vision in both eyes. No participants had a history of neurological or emotional disorders. Participants, being university students, were assumed to read at a satisfactory level, and none was formally diagnosed as having reading impairments.

4.1.3. Stimuli. The stimuli were two new lists of 10 five-letter words, each varying according to the position of the unconnected sub-units relevant to the word's center (right, left), and presented in all possible positions of the initial fixation letter (first, second, third, fourth, and fifth). The words were nouns selected from primary and secondary school textbooks, as well as those occurring in the dictionary with medium frequency $(2.5-3.5)$ in accordance with previous studies (Abdelhadi et al., 2011; Khateb et al., 2014), as judged by 52 university students on a 1-5 frequency scale $(1=$ very rare, $2=$ rare, $3=$ average, 
$4=$ frequent, $5=$ very frequent). The words were displayed in white 24-point Simplified Arabic Fix font on a black background of a PC screen (Table 4). The words were introduced randomly.

4.1.4. Procedure. The procedure was largely same as that of Experiment 1, but included a total numbers of 100 trials.

\subsection{Results}

Because the accuracy percentage exceeded $99 \%$ in all conditions, an analysis of accuracy percentage was not conducted. The differences in reading times for positions of the word's sub-units (right, left) and the initial fixation letter (first, second, third, fourth, fifth) were tested through an RM-ANOVA. We found a significant effect of unconnected sub-unit position (right, left $)(\mathrm{F}(1,33)=5.43$, $\mathrm{p}<0.03$ ), with reaction time for right positioned unconnected sub-units $($ Mean $=397$, $\mathrm{SD}=141)$ shorter than for corresponding left sub-units $($ Mean $=412, \mathrm{SD}=126)$. The effect of the initial fixation letter was also significant $(\mathrm{F}(4,30)=7.04, \mathrm{p}<0.0001)$, with Post- hoc paired sample $t$-tests showing that the reaction time for the second and third fixation letters is similar but shorter than that for the first, fourth, and fifth fixation letters. All other interactions between the factors were non-significant (Figure 5).

Figure 5. Reaction time for five-letter words as a function of the initial fixation letter (first, second, third, fourth, and fifth). Note: Error bars represent standard error

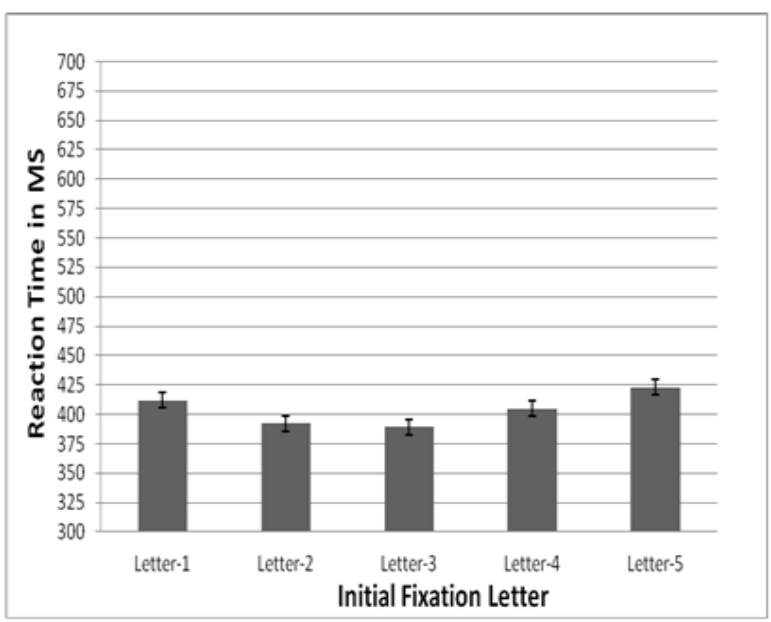

\subsection{Discussion}

For five letter words, we observed a Ushaped curve of reaction time, as a function of initial viewing position with a minimum towards the second and third letter in accordance with Experiments 3, 4 and 5. Taking into account the retinal drop in visual acuity and the increased difficulty to recognize a five letter word with a single fixation, the likelihood of an OVP effect is increased in long words (five letter words). Additionally, the word's information distribution (root and suffix) contributed to the emergence the OVP effect in five letter words.

As in the previous experiments 1 and 2 a perceptual superiority was found for partially connected/unconnected four letter Arabic words with right-positioned unconnected subunits as compared to left positioned unconnected sub-units. This occurred because differential discriminability into the right/left of fixation and hemispheric sensitivity to globallocal processing, especially in Arabic.

\section{JOINT ANALYSIS}

A joint analysis of positioned unconnected sub-units within word reaction times for Experiments 1, 2, and 3 were conducted. The within-subjects factor was the position of unconnected sub-units within a word (left, right), and the between-subjects factor was word length (3, 4, 5 letters). The mixed-design RM-ANOVA revealed a significant effect of the position for unconnected sub-units within a word $(F(1,94)=6.31, p<0.05)$, with reaction time for the right positioned unconnected sub-units within words shorter than for their left-positioned counterparts. In addition, a word length effect was found $(\mathrm{F}(2,94)=5.32$, $\mathrm{p}<0.05$ ), with reaction time increasing with increases in word length. The interaction between factors was found to be non-significant $(\mathrm{F}(2,94)=1.288, \mathrm{p}=0.281)($ Figure 6$)$.

Figure 6. Reaction time as a function of unconnected sub-unit position (right, left) and word length (3, 4,5 letters). Note: Error bars represent standard error

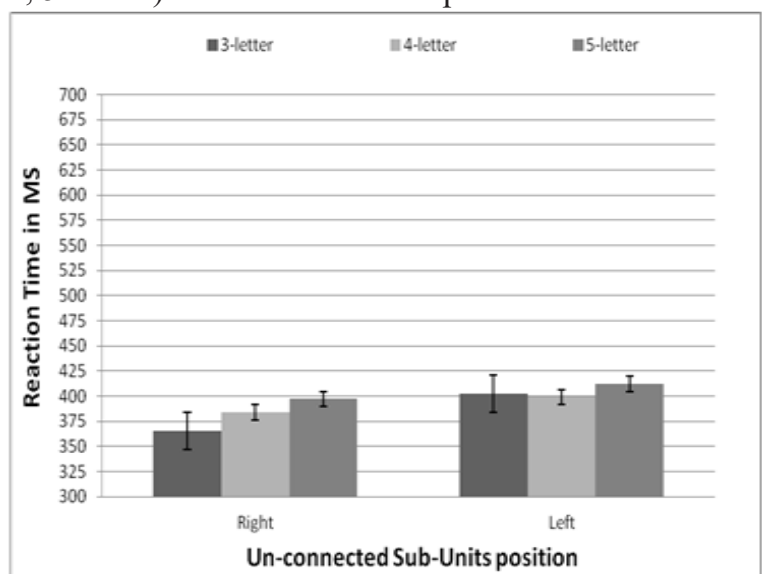




\section{GENERAL DISCUSSION}

The present study explores how initial viewing position affects the processing of isolated Arabic word. In the present series of experiments, we systematically manipulated the initial word viewing position by shifting words horizontally relative to an imposed initial viewing position. Variations in recognition and processing time were measured as a function of initial viewing position. In a series of three experiments, stimuli were partially connected/ unconnected words of varying lengths $(3,4,5$ letters) with participants being asked to perform a recognition task. We explored how initial viewing position affected word processing efficiency. Overall, the results were consistent with previous findings on central OVP (Brysbaert and Nazir, 2005; Deutsch and Rayner, 1999; Farid and Grainger, 1996; Hyönä and Bertram, 2011; O'Regan and Jacobs, 1992; O'Regan et al., 1984; Van der Haegen et al., 2010; Vitu, O'Regan and Mittau, 1990). The OVP for processing isolated Arabic words tends to be in the center of the word (second or third letter), where naming time is minimal. For four- and five- letter words, we observed a U-shaped curve of reaction time, as a function of initial viewing position with a minimum towards the second and third letter. As the fixation position deviated from the OVP, time cost increased (O'Regan et al., 1984). For threeletter words, no OVP effect was observed and all reaction times were similar.

Many factors may contribute to the OVP effect, and we will discuss their potential influence on Arabic OVP effects below.

Visual acuity limitations may explain the OVP effect. Previous research has argued that the decrease in visual acuity with retinal eccentricity contributes to the OVP effects of word recognition; this occurs because visual acuity decreases with greater letter distance from the fixation position, resulting in a loss of visual information (Brysbaert and Nazir, 2005; Nazir, 1991; Rayner, 2009; Vitu, Lancelin and d'Unienville, 2007). When participants were required to fixate on the first or last letters of words, visual acuity limitations reduced their ability to recognize them. Thus, in the present study, response times were longer for fourand five-letter words when the initial fixation fell on the first and last letters than when it fell on other letters.

However, no OVP effect was found for three letters. These words fell within the fovea in the visual span; since visual acuity drops off rapidly with retinal eccentricity, most letters of a short word can be seen in a single glance when fixating on the word center. With longer words (e.g., four or five letters words), it becomes more difficult to recognize all letters with a single fixation position, which increases the likelihood of an OVP effect (Hyönä and Bertram, 2011). Recently, White et al. (2012) found that there was no OVP for two-character kanji words. It seems that the OVP effect is more evident in extrafoveal locations, with no OVP effects observed for foveal locations (Almabruk et al., 2011; Liu and Li, 2013).

Arabic readers found it easier to recognize a word when the fixation position was located at the second or third letters. These results suggest that word beginning may play an important role in recognition OVP effect. Prior studies have demonstrated that the word beginning is more informative than the word ending for word recognition (Broerse and Zwaan, 1966; Brysbaert and Nazir, 2005; Eriksen and Eriksen, 1974; Li and Pollatsek, 2011; White et al., 2008; Yan et al., 2006). Fixating at the word beginning makes recognition easier because eyes tend to land at word beginnings and frequently fixated locations improve reading performance (Brysbaert and Nazir, 2005; Nazir et al., 2004). Thus, because the most information used for word recognition can be extracted between the word's beginning and its center, the initial fixation position occurred between the word beginning and center (i.e., at the second and third letters of 4-letter and 5-letter words).

Perceptual learning based on reading habits (Yan et al., 2006; Deutsch and Rayner, 1999; Farid and Grainger, 1996; Nazir et al., 2004; Wong and Hsiao, 2012) does not account for the word recognition OVP effect observed in this study. Because Arabic is read from right to left, words are repeatedly recognized in the same location in the visual field. As a result, word recognition is more effective when the initial fixation occurs at the position that readers most often fixate on while reading (Yan et al., 2006; Ducrot and Pynte, 2002). According to the reading habit hypothesis, the leftward asymmetry of the initial fixation curve is due to the increased average visibility of letters to the right of the fixation position (compared to letters to the left of the fixation position). This asymmetry in letter visibility is typically attributed to the influence of reading habits on the deployment of attention, with a rightward bias induced in languages that are read from left to right. Therefore, this hypothesis incorrectly predicted that the Arabic initial fixation curve would be asymmetric to the right. This 
hypothesis was based on the assumption that because of a leftward bias in the deployment of attention (in a language that is read from right to left), letters would be more visible to the left of the fixation position, giving an advantage to fixations that are to the right of the word's center.

Prior research on left-to-right languages such as English, French, and German has shown a systematic leftward asymmetry in OVP. According to the hemispheric specialization hypothesis, the leftward asymmetry is because leftward fixations leave more of the word in the right visual field. This leads information extracted from a greater proportion of the word to be directly transmitted to the left hemisphere, where the principal neural structures subtending visual word recognition are located. This hypothesis incorrectly predicted that a leftward asymmetry should also be observed in Arabic since speakers of Arabic presumably also have language structures lateralized in the left hemisphere. The results of our experiments showed, however, that the average initial fixation curve is central for Arabic words.

According to this view, all information to the left of the fixation position will project unilaterally to the right hemisphere $(\mathrm{RH})$, at least during initial processing, and all information to the right of the fixation will project unilaterally to the left hemisphere (LH). Since it has been established that the LH generally has superior word-perception capabilities to the RH (Almabruk et al., 2011), this putative division in hemispheric processing at the point of fixation has been claimed to have important effects on word recognition (Ellis and Brysbaert, 2010). In particular, information projected separately to each hemisphere from each side of the fixation position is integrated in the language-dominant LH (for the majority of individuals) via interhemispheric transfer prior to lexical processing (e.g., Brysbaert, 1994, 2004; Brysbaert and Nazir, 2005; Hunter et al., 2007; Van der Haegen et al., 2010). Thus, when the majority of letters in a fixated word falls to the right of the fixation position, it creates a perceptual advantage, because these letters project directly to the $\mathrm{LH}$, with less information having to undergo disruptive interhemispheric transfer prior to recognition.

Moreover, like Latinate languages, Arabic produces perceptual superiority for words displayed to the right of the fixation position, indicating classic LH dominance for processing words (Ibrahim and Eviatar, 2009). Arabic is written using a cursive script that decreases the distinctiveness of individual letters within words. This introduces additional crowding (Jordan, Paterson and Almabruk, 2010; Pelli et al., 2007), which may further decrease letter resolution (Eviatar et al., 2004; Ibrahim, Eviatar and Aharon-Peretz, 2002).

When partially connected/unconnected Arabic words were presented in lateralized displays in all possible letter positions (Experiments $2,4,6$ ), a perceptual superiority was found for words with right-positioned unconnected sub-units as compared to left positioned unconnected sub-units. This occurred because letter discriminability into the right of fixation locations is especially good (Jordan and Paterson, 2009; Jordan and Paterson, 2010) and because of the different processing of the whole word form on each hemisphere (Hsiao et al., 2013). Such findings support the established view that states the LH specialize in word recognition for alphabetic languages; it also provides further evidence that an $\mathrm{LH}$ advantage also occurs for languages that are read from right to left, such as Arabic (Ibrahim and Eviatar, 2009).

Furthermore, we also observed a word length effect consistent with results of previous English studies (Joseph, Liversedge, Blythe, White and Rayner, 2009; Plummer and Rayner, 2012; Rayner et al., 2011). The word length effect has been considered as an evidence for sequential process (Eviatar and Zaidel, 1991; Iacaboni and Zaidel, 1996; Reichle, Rayner and Pollatsek, 2006), while its absence in skilled readers indicates parallel letter processing in word recognition (Aghababian and Nazir, 2000; LaBerge and Samuels, 1974). Its presence in recognition of partially connected/unconnected Arabic words supports the analytic-sequential processing and the non-lexical route in reading. Our findings provide original evidence suggesting inhibitory effects of word length (longer words are harder) in Arabic.

It is worth to note that, although word stimuli were presented repeatedly in different fixation positions, possible repetition effects can be discarded since all word stimuli were repeated the same number of trials in each experiment, and especially since a word length effect was found. Even though long words were repeated more often than short words since they include more letter positions (3-letter words were presented in 3 fixation positions, 4-letter words were presented in 4 fixation positions, 5-letter words were presented in 5 fixation positions) it took a longer time to recognize them. 
Several limitations must be considered when interpreting the results. Prior studies have explored the effect of reading direction and morphological structure on OVP effects (Deutsch and Rayner, 1999; Nazir et al., 2004). Farid and Grainger (1996) found that the initial fixation curves in Arabic depended on the morphological structure of the stimuli. Prefixed words produced a leftward (word ending) advantage whereas suffixed words produced a rightward (word beginning) advantage. In the present study, we used words with the first, second and third letters to be root letters. Indeed, root letters that are of special importance for word recognition are concentrated in our study towards the beginning (as in Latinate languages). Previous studies raised the question of how the distribution of critical information across a word (as manipulated with morphological structure) does play a role in shaping the initial fixation curve and may influence the OVP effects in Arabic; this will need further investigation. Additionally, in the present study we used only three, four, five letter words. Despite the fact that most Arabic words are of the above word lengths (Belaid and Choisy, 2008), this may not allow the generalizability of our findings to other word lengths (such as two, six, seven, etc.). Furthermore, in the present study we did not use all forms of partially connected /unconnected Arabic words and Future research should investigate the OVP effect for these word forms. Finally, to our knowledge, no systematic data exist on word form frequency in Arabic, so we cannot address any possible effects of word form frequency with our findings.

\section{CONCLUSION}

The present study found that OVP effects occurred during the processing of isolated Arabic words. In Arabic, the OVP may be in the center of the word. No OVP was found in three-letter words; for four- and five-letter words, the OVP effect appeared as a U-shaped curve with a minimum towards the second and third letters. The present research may be the first systematic study to explore OVP effects in the processing of isolated partially connected/unconnected Arabic words, and may help elucidate Arabic visual word recognition. We also note that letter visibility and/or lexical constraints might play critical roles in word recognition OVP effects during the processing of isolated partially connected/unconnected Arabic words and letters.
Additionally, the present experiments suggest that a systematic study of visual features, OVP, and word length in Arabicread from right to left-provides appropriate means of testing our hypotheses. The results from the present experiments indicate that the reading habit hypothesis is lacking, while the hemispheric specialization, lexical constraint and letter visibility hypothesis merit further elaboration and testing.

\section{ACKNOWLEDGMENTS}

This work was carried out under the supervision of Prof. Michal Lavidor, Department of Psychology, Bar-Ilan University. I would especially like to thank my supervisor Prof. Michal Lavidor, whose insights and guidance continually challenged me throughout this experience. I wish to thank her for all the time and effort she invested in me and for all the freedom she gave me to pursue my ideas throughout this gratifying process.

\section{Conflicts of Interest}

Author declares no conflict of interest.

\section{REFERENCES}

Abd El-Minem, F. M. (1987). Elm al-sarf. Jerusalem: Al-Taufik Press [in Arabic].Abu-Rabia, S. (2001). The role of vowels in reading Semitic scripts: Data from Arabic and Hebrew. Reading and Writing: An Interdisciplinary Journal, 14, 39-59.

Abu-Rabia, S. (2001). The role of vowels in reading Semitic scripts: Data from Arabic and Hebrew. Reading and Writing: An Interdisciplinary Journal, 14, 39-59.

Abdelhadi, S., Ibrahim, R. \& Eviatar, Z. (2011). Perceptual load in the reading of Arabic: Effects of orthographic visual complexity on detection. Writing Systems Research 3, 117-127.

Adamson, M. M. \& Hellige, J. B. (2006). Hemispheric differences for identification of words and nonwords in Urdu-English bilinguals. Neuropsychology, 20, 232-248.

Aghababian, V. \& Nazir, T.A. (2000). Developing normal reading skills: Aspects of the visual processes underlying word recognition. Journal of Experimental Child Psychology, 76, 123-150.

Almabruk, A. A. A., Paterson, K. B., McGowan, V. A., Jordan, T. R. (2011). Evaluating effects of divided hemispheric processing on word recognition in foveal and extrafoveal displays: The evidence from Arabic. PLoS ONE 6(4): e18131.

Belaid, A. \& Choisy C. (2008). Human Reading Based Strategies for Off-Line Arabic Word Recognition. Arabic and Chinese Handwriting Recognition Lecture Notes in Computer Science, 4768, 36-56.

Blommaert, F. J. (1988). Early-visual factors in letter 
confusions. Spatial Vision, 3, 199-224.

Bouma, H. (1971). Visual recognition of isolated lowercase letters. Vision Research, 11, 450-474.

Bouma, H. (1973). Visual interference in the parafoveal recognition of initial and final letters of words. Vision Research, 13(4), 767-782.

Briggs, R. \& Hocevar, D. J. (1975). A new distinctive feature theory for upper case letters. Journal of General Psychology, 93, 87-93.

Broerse, A. C. \& Zwaan, E. J. (1966). The information value of initial letters in the identification of words. Journal of Verbal Learning and Verbal Behavior, 5, 441-446.

Brysbaert, M. \& Nazir, T. A. (2005). Visual constraints in written word recognition: Evidence from the optimal viewing-position effect. Journal of Research in Reading, 28, 216-228.

Brysbaert, M. (1994). Interhemispheric transfer and the processing of foveally presented stimuli. Behavioral Brain Research, 64, 151-161.

Brysbaert, M. (2004). The importance of interhemispheric transfer for foveal vision: A factor that has been overlooked in theories of visual word recognition and object perception. Brain and Language, 88, 259-267.

Brysbaert, M., Vitu, F. \& Schroyens, W. (1996). The right visual field advantage and the optimal viewing position effect: On the relation between foveal and parafoveal word recognition. Neuropsychology, 10, 385-395.

Cattell, J. M. (1886). The time taken up by cerebral operations. Mind, 11, 377-392.

Chung, S. T. L., Legge, G. E. \& Cheung, S. H. (2004). Letter-recognition and reading speed in peripheral vision benefit from perceptual learning. $\mathrm{Vi}$ sion Research, 44(7), 695-709.

Clark, J. J. \& O’Regan, J. K. (1999). Word ambiguity and the optimal viewing position in reading. $\mathrm{Vi}$ sion Research, 39, 843-857.

Coltheart, M. (2005). Modeling Reading: The dualroute approach. In M. Snowling \& C. Hulme (Eds.). The science of reading: A handbook (pp. 6-23). Oxford, England: Blackwell.

Coltheart, M., Rastle, K., Perry, C., Langdon, R., \& Ziegler, J. (2001). DRC: A dual route cascaded model of visual word recognition and reading aloud. Psychological Review, 108(1), 204-256.

Deutsch, A. \& Rayner, K. (1999). Initial fixation location effects in reading Hebrew words. Language and Cognitive Processes, 14, 393-421.

Ducrot, S. \& Pynte, J. (2002). What determines the eyes' landing position in words? Perception \& Psychophysics, 64, 1130-1144.

Ehri, C. L. \& Snowling, J. M. (2005). Develop mental variations in word recognition. In C. A. Stone, R. E.

Ehri, L. (2005). Development of sight word reading: Phases and findings. In Snowling M. \& Hulme C. (Eds.). The science of reading: a handbook (pp. 135-154). Oxford: Blackwell Publishing.

Ellis, A. W. \& Brysbaert, M. (2010). Split fovea theory and the role of the two cerebral hemispheres in reading: A review of the evidence. Neuropsychologia, 48(2), 353-365.

Eriksen, B. A. \& Eriksen, C. W. (1974). The importance of being first: A tachistoscopic study of the contribution of each letter to the recognition of four-letter words. Perception \& Psychophysics, $15,66-72$.

Eviatar, Z. \& Zaidel, E. (1991). The effects of word length and emotionality on hemispheric contribution to lexical decision. Neuropsychologia, 29, 415-428.

Eviatar, Z., Ibrahim, R. \& Ganayim, D. (2004). Orthography and the hemispheres: Visual and lilnguistic aspects of letter processing. Neuropsychology, 18, 174-184.

Farid, M. \& Grainger, J. (1996). How initial fixation position influences visual word recognition: A comparison of French and Arabic. Brain and Language, 53, 351-368.

Gervais, M. J., Harvey, L. O., Jr. \& Roberts, J. O. (1984). Identification confusions among letters of the alphabet. Journal of Experimental Psychology-Human Perception and Performance, 10, 655-666.

Geyer, L. H. (1977). Recognition and confusion of the lowercase alphabet. Perception \& Psychophysics, 22, 487-490.

Gibson, E. J., Osser, H., Schiff, W. \& Smith, J. (1963). An analysis of critical features of letters tested by a confusion matrix. In A basic research program on reading. Cooperative Research Project No. 639, Cornell University, Ithaca, NY.

Grainger, J. \& Segui, J. (1990). Neighborhood frequency effects in visual word recognition: A comparison of lexical decision and masked identification latencies. Perception and Psychophysics, 47, 191-198.

Grainger, J. (1990). Word frequency and neighborhood frequency effects in lexical decision and naming. Journal of Memory and Language, 29, 228-244.

Grainger, J., O'Regan, J.K., Jacobs, A.M. \& Segui, J. (1989). On the role of competing word units in visual word recognition: The neighborhood frequency effect. Perception and Psychophysics, 45, 189-195.

Hsiao, J. H., Cipollini, B. \& Cottrell, G. (2013). Hemispheric asymmetry in perception: A differential encoding account. Journal of Cognitive Neuroscience, 25(7), 998-1007.

Hunter, Z. R., Brysbaert, M. \& Knecht, S. (2007). Foveal word reading requires interhemispheric communication. Journal of Cognitive Neuroscience, 19(8), 1373- 1387.

Hyönä, J. \& Bertram, R. (2011). Optimal viewing position effects in reading Finnish. Vision Research, $51,1279-1287$

Iacoboni, M. \& Zaidel , E. (1996). Hemispheric independence in word recognition: evidence from unilateral and bilateral presentations. Brain and Language, 53, 121-140.

Ibrahim, R., and Eviatar, Z. (2009). Language status and hemispheric involvement in reading: Evidence from trilingual Arabic speakers tested in Arabic, Hebrew, and English. Neuropsychology, 23(2): 240-254

Ibrahim, R., Eviatar, Z. \& Aharon-Perez, J. (2002). Do the characteristics of Arabic orthography slow its cognitive processing? Neuropsychology, 16, 322-326.

Jordan, T. R. \& Paterson, K. B. (2009). Re-evaluating split-fovea processing in word recognition: A critical assessment of recent research. Neuropsychologia, 47(12), 2341-2353.

Jordan, T. R. \& Paterson, K. B. (2010). Where is the evidence for split fovea processing in word recognition? Neuropsychologia, 48(9), 2782-2783.

Jordan, T. R., McGowan, V. A.,\& Paterson, K. B. (2012). Reading with a filtered fovea: The in- 
fluence of visual quality at the point of fixation during reading. Psychonomic Bulletin \& Review, 19, 1078-1084.

Jordan, T.R., Paterson, K.B., and Almabruk, A.A.A. (2010). Revealing the superior perceptibility of words in Arabic. Perception, 39: 426-428.

Joseph, H. S. S. L., Liversedge, S. P., Blythe, H. I., White, S. J. \& Rayner, K. (2009). Word length and landing position effects during reading in children and adults. Vision Research, 49, 20782086.

Khateb A., Khateb-Abdelgani M., Taha H. Y. \& Ibrahim R. (2014) The impact of orthographic connectivity on visual word recognition in Arabic: A cross-sectional study. Reading and Writing, 6 , $1-24$.

Khateb, A., Taha, H. Y., Elias, I. \& Ibrahim, R. (2013). The effect of the internal orthographic connectivity of written Arabic words on the process of the visual recognition: A comparison between skilled and dyslexic readers. Writing Systems Research, 5, 214-233.

LaBerge, D. \& Samuels, S. J. (1974). Toward a Theory of Automatic Information Processing in Reading. Cognitive Psychology, 6, 293-323.

Lavidor, M. \& Walsh, V. (2004). Opinion - The nature of foveal representation. Nature Reviews Neuroscience, 5(9), 729-735.

Lavidor, M., Ellis, A. W., Shillcock, R., \& Bland, T. (2001). Evaluating a split processing model of visual word recognition: Effects of word length. Cognitive Brain Research, 12, 265-272.

Legein, C. H. \& Bouma, H. (1977). Dyslectic and normally-reading children. I. Exploration of a lettersearch test for screening purposes. II. Follow-up and further exploration in 4 weak and 4 normal readers on letter, word and number recognition. Documenta Ophthalmologica, 42(2), 391-396.

Legge, G. E., Mansfield, J. S. \& Chung, S. T. L. (2001). Psychophysics of reading: XX. Linking letter recognition to reading speed in central and peripheral vision. Vision Research, 41(6), 725 743.

Li, X. \& Pollatsek, A. (2011). Word knowledge influences character perception. Psychonomics Bulletin \& Review, 18, 833-839.

Lindell, A. K. \& Nicholls, M. E. R. (2003). Cortical representation of the fovea: Implications for visual half-field research. Cortex, 39(1), 111-117.

Liu, P. \& Li, X. (2013). Optimal viewing position effects in the processing of isolated Chinese words. Vision Research. 81, 45-57

Loomis, J. M. (1982). Analysis of tactile and visual confusion matrices. Perception \& Psychophysics, 31, 41-52.

Martin, C. D., Thierry, G., Démonet, J. F., Roberts, M., \& Nazir, T. (2007). ERP evidence for the split fovea theory. Brain Research, 1185, 212-220.

Nazir, T. A. (1991). On the role of refixations in letter strings: The influence of oculomotor factors. Perception \& Psychophysics, 49, 373-389.

Nazir, T. A., Ben-Boutayab, N., Decoppet, N., Deutsch, A. \& Frost, R. (2004). Reading habits, perceptual learning, and recognition of printed words. Brain and Language, 88, 294-311.

Nazir, T. A., Heller, D. \& Sussmann, C. (1992). Letter visibility and word recognition: The optimal viewing position in printed words. Perception \& Psychophysics, 52(3), 315-328.

Nazir, T. A., Jacobs, A. M. \& O'Regan, J. K. (1998)
Letter legibility and visual word recognition. Memory \& Cognition, 26(4), 810-821.

O'Regan, J. K. \& Jacobs, A. M. (1992). Optimal viewing position effect in word recognition: A challenge to current theory. Journal of Experimental Psychology: Human Perception and Performance, 18, 185-197.

O’Regan, J. K., Levy-Schoen, A., Pynte, J. \& Brugaillere, B. (1984). Convenient fixation location within isolated words of different length and structure. Journal of Experimental Psychology: Human Perception and Performance, 10(2), 250-257.

Paterson, K. B., Jordan, T. R. \& Kurtev, S. (2009). Binocular Fixation Disparity in Single Word Displays. Journal of Experimental PsychologyHuman Perception and Performance, 35(6), 1961-1968.

Pelli, D. G., Tillman, A. K., Freeman , J., Su, M., Berger, D., Tracey \& Majaj, J. N. (2007). Crowding and Eccentricity Determine Reading Rate. Journal of Vision, 7(2), 1-36.

Plummer, P. \& Rayner, K. (2012). Effects of parafoveal word length and orthographic features on initial fixation landing positions in reading. Attention Perception \& Psychophysics, 74, 950-963.

Rayner, K. (1979). Eye guidance in reading: Fixation locations within words. Perception, 8, 21-30.

Rayner, K. (1998). Eye movements in reading and information processing: 20 years of research. Psychological Bulletin, 124(3), 372-422.

Rayner, K. (2009). Eye movements and attention in reading, scene perception, and visual search. The Quarterly Journal of Experimental Psychology, 62, 1457-1506.

Rayner, K., Slattery, T. J., Drieghe, D. \& Liversedge, S. P. (2011). Eye movements and word skipping during reading: Effects of word length and predictability. Journal of Experimental Psychology: Human Perception and Performance, 37, 514-528.

Reichle, E. D., Rayner, K. \& Pollatsek, A. (2006). E-Z Reader: A cognitive-control, serial-attention model of eye-movement control during reading. Cognitive Systems Research, 7, 4-22.

Shillcock, R., Ellison, T. M. \& Monaghan, P. (2000). Eye-fixation behavior, lexical storage, and visual word recognition in a split processing model. Psychological Review, 107(4), 824-851.

Stevens, M. \& Grainger, J. (2003). Letter visibility and the viewing position effect in visual word recognition. Perception \& Psychophysics, 65, 133151.

Stone, C. A. (2004). Handbook of language and literacy: Development and disorders. Guilford Press.

Stuart, M., Masterson, J., Dixon, M. \& Quinlan, P. (1999). Inferring sublexical correspondences from sight vocabulary: Evidence from 6- and 7-year-olds. Quarterly Journal of Experimental Psychology A, 52(2), 353-366.

Taha, H., Ibrahim, R. \& Khateb, A. (2013). How does Arabic orthographic connectivity modulate brain activity during visual word recognition: An ERP study. Brain Topography, 26, 292-302.

Taouk, M. \& Coltheart, M. (2004).The Cognitive Processes Involved in Learning to Read in Arabic. Reading and Writing, 17 (1-2), 27-57.

Townsend, J. T. \& Ashby, F. G. (1982). Experimental test of contemporary mathematical models of visual letter recognition. Journal of Experimen- 
tal Psychology-Human Perception and Performance, 8, 834-854.

Townsend, J. T. (1971a). Theoretical analysis of the alphabetic confusion matrix. Perception \& Psychophysics, 9, 40-50.

Townsend, J. T. (1971b). Alphabetic confusion: a test of models for individuals. Perception \& Psychophysics, 9, 449-454.

Townsend, J. T., Hu, G. G. \& Evans, R. J. (1984). Modeling feature perception in brief displays with evidence for positive interdependencies. Perception \& Psychophysics, 36, 35-49.

Van der Haegen, L. \& Brysbaert, M. (2011). The mechanisms underlying the interhemispheric integration of information in foveal word recognition: Evidence for transcortical inhibition. Brain and Language, 118(3), 81-89.

Van der Haegen, L., Drieghe, D. \& Brysbaert, M. (2010). The split fovea theory and the leicester critique: What do the data say? Neuropsychologia, 48, 96-106.

Vellutino, F. R., Fletcher, J. M., Snowling, M. J. \& Scanlon, D. M. (2004). Specific reading disability (dyslexia): What have we learned in the past four decades? Journal of Child Psychology and Psychiatry, 45(1), 2-40.

Vitu, F., Lancelin, D. \& d'Unienville, V. M. (2007). A perceptual-economy account for the invertedoptimal viewing position effect. Journal of Experimental Psychology: Human Perception and Performance, 33, 1220-1249.

Vitu, F., O’Regan, J. K. \& Mittau, M. (1990). Optimal landing position in reading isolated words and continuous texts. Perception \& Psychophysics, 47, 583-600.

Watson, A. B. \& Fitzhugh, A. E. (1989). Model ling character legibility. Society for Information Display Digest of Technical Papers, 20, 360-363.

Wertheim, T. (1894). Uber die indirekte Sehscha"rfe. Zeitschrift für Psychologie, 7, 172.

White, S. J., Hirotani, M. \& Liversedge, S. P. (2012). Eye movement behaviour during reading of Japanese sentences: Effects of word length and visual complexity. Reading and Writing, 25, 981-1006.

White, S. J., Johnson, R. L., Liversedge, S. P. \& Rayner, K. (2008). Eye movements when reading transposed text: The importance of word-beginning letters. Journal of Experimental Psychology: Human Perception and Performance, 34, 12611276.

Whitney, C. (2001). How the brain encodes the order of letters in a printed word: The SERIOL model and selective literature review. Psychonomic Bulletin \& Review, 8(2), 221-243.

Whitney, D. \& Levi, D. M. (2011). Visual crowding: A fundamental limit on conscious perception and object recognition. Trends in Cognitive Sciences, 154

Wong, Y. K. \& Hsiao, J. H. (2012). Reading direction is sufficient to account for the optimal viewing position in reading: The case of music reading. Paper presented at The 34th Annual Conference of the Cognitive Science Society (CogSci2012), Sapporo, Japan.

Yan, G., Tian, H., Bai, X. \& Rayner, K. (2006). The effect of word and character frequency on the eye movements of Chinese readers. British Journal of Psychology, 97, 259-268.

Yao-N'Dré, M., Castet, E. \& Vitu, F. (2013). The opti- mal viewing position effect in the lower visual field. Vision Research, 76, 114-123. 
(IJCRSEE) International Journal of Cognitive Research in Science, Engineering and Education Vol. 3, No.2, 2015. 